\title{
The effect of electronic prescribing and medication administration on nurses' workflow and activities: an uncontrolled before and after study
}

\author{
Astrid Van Wilder ${ }^{1}$, Helen Bell ${ }^{2^{*}}$ (D) and Bryony Dean Franklin ${ }^{1,2}$
}

\begin{abstract}
Background: Electronic prescribing and medication administration (ePMA) is purported to improve patient safety through a number of benefits including reducing medication errors and facilitating identification of prescribers. However little is known of its effect on nurses' workflow and the associated patient safety implications. Our objective was to explore differences in drug round duration, medication administration workflow and activities, interruptions, and timeliness of medication administration before and after implementation of ePMA.

Methods: The study was an uncontrolled before and after study starting one month before and continuing until one month after implementation of ePMA, in a medicine for the elderly ward in a UK teaching hospital. Observation of nursing staff and documentation of workflow patterns, activities, interruptions and timeliness of medication administration during 20 scheduled drug rounds pre-ePMA and 14 rounds afterwards.

Results: While the introduction of ePMA did not significantly affect drug round duration, it altered the distribution of tasks with a doubling of the time spent on documentation. As might be expected, it eliminated time spent searching for paper drug charts. While there was no significant change in interruption rate, the types of interruption changed with an increase in healthcare related interruptions and a decrease in non-healthcare related interruptions. The timeliness of medication administration improved.

Conclusion: This small exploratory study suggests that introduction of ePMA does not significantly affect drug round duration, but alters the time spent on different tasks. The timeliness of medication administration improved, with potential benefits to patient safety.
\end{abstract}

Keywords: ePMA, Nurses' workflow, Interruptions, Activities, Drug round duration, Inpatient setting

\section{Background}

Electronic prescribing and medication administration (ePMA) has been defined as "the utilisation of electronic systems to facilitate and enhance the communication of a prescription or medication order, aiding the choice, administration and supply of a medicine through information and decision support and providing a robust audit trail for the entire medicines process" [1]. ePMA is often cited as having a number of benefits, such as increasing

\footnotetext{
* Correspondence: Helen.Bell@imperial.nhs.uk

${ }^{2}$ Centre for Medication Safety and Service Quality, Imperial College Healthcare NHS Trust, London, UK

Full list of author information is available at the end of the article
}

efficiency and reducing medication errors [1-4]. In 2011, 13 \% of 101 English hospitals had ePMA across all medical and surgical wards [5]; this figure is now likely to be higher.

While a few studies have explored the effects of ePMA on nurses' work in a hospital setting, those conducted to date mainly originate from the USA $[6,7]$ where systems of prescribing, dispensing and administration are very different to those in the UK [8]. Within the UK, Barber et al. [9] explored nurses' attitudes towards ePMA implementation, noting reluctance before implementation which changed to acceptance afterwards. Other international studies [10-13] suggest that ePMA may have a 
negative effect on communication between nurses and doctors [10] and impede work patterns [11]. Little is known about the effect on nurses' work during drug rounds. An Australian study suggests that nurses spent an increased proportion of time reviewing medication following introduction of ePMA, but this was offset by a decrease in nearly all other medication related tasks [12]. There is no consensus of the effects of ePMA on nurses' workflow [14]; it has also been suggested that any effects seen on work practices may be due to individual nurses' behaviour [15].

We wanted to explore how ePMA may affect different aspects of nurses' work, relating to both workload and patient safety, in the UK hospital setting. In this exploratory study, our objectives were to compare the following, before and after implementation of ePMA, in a UK hospital ward:

- Drug administration round duration;

- Nurses' activities and workflow relating to medication administration;

- Interruptions during the drug round;

- Timeliness of medication administration.

\section{Methods}

\section{Setting}

The study took place on a 14-bed medicine for the elderly ward in a London teaching hospital. The ward was one of the first two wards in the hospital to adopt ePMA, a component of a commercially available hospital information system that was already in use. Patients were generally transferred from other clinical areas using paper drug charts and medications were transcribed by medical staff onto the ePMA system. The hospital operated a typical UK system for dispensing medication to hospital inpatients, with a combination of ward stock, individual patient dispensing and the use of patients' own medication. The hospital's medication administration policy states that medication must be administered within two hours either side of its scheduled administration time.

Scheduled drug rounds generally took place four times a day. Before ePMA implementation, medication was generally scheduled to be administered at 8 am (morning), $12 \mathrm{pm}$ (noon), $2 \mathrm{pm}$ (usually intravenous (IV) medication), $6 \mathrm{pm}$ (evening) and $10 \mathrm{pm}$ (night). However medications scheduled to be given at 12 noon and 2 pm were generally administered during the same drug round at approximately $1 \mathrm{pm}$. During drug rounds, each patient was visited in turn by the nurse responsible for that part of the ward. A drug round typically included beds in one bay, plus a side room, giving a total of 7 beds if all were occupied. Ward stock medications were stored in a medication trolley; patients' own and individually dispensed medications were in bedside medication lockers for each patient. A paper drug chart was kept at the end of each patient's bed.

After introduction of ePMA, the main changes were that nurses used computers on wheels during medication administration, some of which also incorporated a medication trolley, and medication was generally scheduled to be administered at $8 \mathrm{am}, 2 \mathrm{pm}, 6 \mathrm{pm}$ and $10 \mathrm{pm}$.

\section{Study design}

We used an uncontrolled before and after study design, observing drug administration rounds every two days starting one month before and continuing until one month after ePMA implementation. Data collection started 25 February 2015 and continued until 26 April 2015; ePMA went live at midday on 23 March.

\section{Data collection}

Observations were conducted by a pharmacy student, aiming to collect data across a range of scheduled drug rounds, and to be as unobtrusive as possible. Nurses gave verbal consent prior to being observed. The study was approved locally as a service evaluation; research ethics approval was not required. Data were collected on four aspects:

\section{Drug administration round duration}

Drug administration rounds were timed and included the time taken to prepare medication as well as the time taken to administer it.

\section{Nurses' activities and workflow relating to medication administration}

The observer used two-dimensional random interval work sampling [16], where the two dimensions were (1) activity, and (2) who the activity was with. The times at which these were recorded were generated using a random interval signal generator that produced a discreet signal 32 times an hour, with the times between successive signals randomly distributed according to the exponential distribution. The pre-piloted data collection form, with activity categories adapted from previous work with pharmacists [17] and local pilot work, is presented in Additional file 1. Nurses' workflow as they moved around the ward was also documented using spaghetti diagrams, which are visual representations of travel patterns [15]. These were drawn by hand onto an outline map of the ward during the observed drug rounds.

\section{Interruptions during the drug round}

The observer documented the number and source of interruptions that nurses experienced during drug rounds, using categories developed from those used 
elsewhere [15]. An interruption was defined as a break in the performance of a human activity initiated by a source internal or external to the recipient, where this break results in the suspension of an initial task in order to begin performance of an unplanned task [18]. Both externally initiated and selfinitiated interruptions were included.

\section{Timeliness of medication administration}

We documented the time at which each dose of medication was administered and the time at which it was due. This was recorded only for those doses that the observer could clearly confirm as being given/not given.

\section{Analysis}

The mean drug round duration was calculated before and after introduction of ePMA. Quantitative activity data were transcribed to a spread sheet and the percentage of time spent on each documented activity was estimated together with $95 \%$ confidence intervals (CI) [19]. If CIs overlap there is no statistically significant difference; if there is no overlap the difference is considered to be statistically significant [20]. Spaghetti diagrams were sorted into different drug round times, before and after ePMA, and visually compared. The total number of interruptions were calculated, plotted graphically and compared, as was the timeliness of medication administration before and after ePMA.

\section{Results}

A total of 20 drug rounds were observed pre-ePMA, accounting for $22 \mathrm{~h}$ of observations. Post-ePMA, 14 drug rounds were observed, accounting for $18 \mathrm{~h}$ of observations (Table 1). Nine different nurses were observed preePMA, of whom four were observed multiple times. Eleven were observed post-ePMA, of whom three were observed multiple times. Five were observed both preand post-ePMA.

\section{Drug administration round duration}

Pre-ePMA the mean drug round time was $67 \min (95 \%$ CI 60 to $82 \mathrm{~min}$ ), post-ePMA it was $77 \mathrm{~min}(95 \% \mathrm{CI} 62$ to $92 \mathrm{~min}$ ); this difference is not statistically significant (as indicated by the overlapping CIs).

Table 1 Drug rounds observed

\begin{tabular}{lll}
\hline Drug round & Before ePMA & After ePMA \\
\hline Morning & $7(35 \%)$ & $7(50 \%)$ \\
Noon/2 pm & $7(35 \%)$ & $4(29 \%)$ \\
Evening & $4(20 \%)$ & $2(14 \%)$ \\
Night & $2(10 \%)$ & $1(7 \%)$ \\
Total: & $20(100 \%)$ & $14(100 \%)$ \\
\hline
\end{tabular}

ePMA electronic prescribing and medication administration
Generally the morning round (pre-ePMA mean 75 min and range 39-125 min; post-ePMA mean $76 \mathrm{~min}$ and range $50-115 \mathrm{~min}$ ) was slightly longer than other drug rounds. Figure 1 presents the duration of morning drug rounds over time, as a time series, and shows wide day-today variation.

\section{Nurses' activities and workflow relating to medication administration}

Pre-ePMA, the $22 \mathrm{~h}$ observed resulted in 497 work sampling points. Post-ePMA, the $18 \mathrm{~h}$ observed resulted in 438 sampling points. The percentage of these sampling points during which the observed nurse was engaged in each type of activity is shown in Fig. 2.

Both pre- and post-ePMA, the highest percentage of time was spent preparing medication. The main difference following introduction of ePMA was a statistically significant increase in the percentage of time spent on documentation, which increased from $9.5 \%(95 \% \mathrm{CI}$ $6.9 \%-12.0 \%$ ) to $20.3 \%$ (95 \% CI $16.6 \%-24.1 \%$ ) of nursing time. The following changes were also statistically significant: 'Searching for patients' drug charts' which reduced from $1.2 \%$ (95\% CI $0.3 \%-2.2 \%$ ) to zero, 'counselling on medication' which reduced from $1.6 \%$ (95 \% CI $0.5 \%-2.7 \%$ ) to zero and 'supervision/education of a student' which reduced from $2.8 \%$ (95\% CI $1.4 \%$ $4.3 \%)$ to zero. The change in time spent supervising students is due to the student nurses' rotations changing over the course of the study which meant that no students remained on the wards following ePMA implementation.

Activities were mainly carried out by the nurse by him or herself, followed by 'other nurses' and 'healthcare assistants', there were no statistically significant changes in this respect (Fig. 3).

Assessment of the spaghetti diagrams (examples presented in Figs. 4 and 5) suggested that most walking took place between patients' beds, moving from the patient's medication locker to the medication trolley, back and forwards to the treatment room to prepare and retrieve medication, and to the kitchen to retrieve equipment such as spoons and cups to administer medication. Based on a visual comparison, there was no obvious difference pre- and post-ePMA; differences seemed due to individual nurses' work practices. For example, preePMA some documented medication administration after administration; others documented after preparation of the dose but before the patient had actually taken it and then returned after the drug round to alter the documentation if the patient did not subsequently take their medication. Some nurses briefly looked at the drug charts at the start of the drug round and collected most of the necessary tools and medication beforehand, potentially making the drug rounds shorter and decreasing the distance covered per round. 


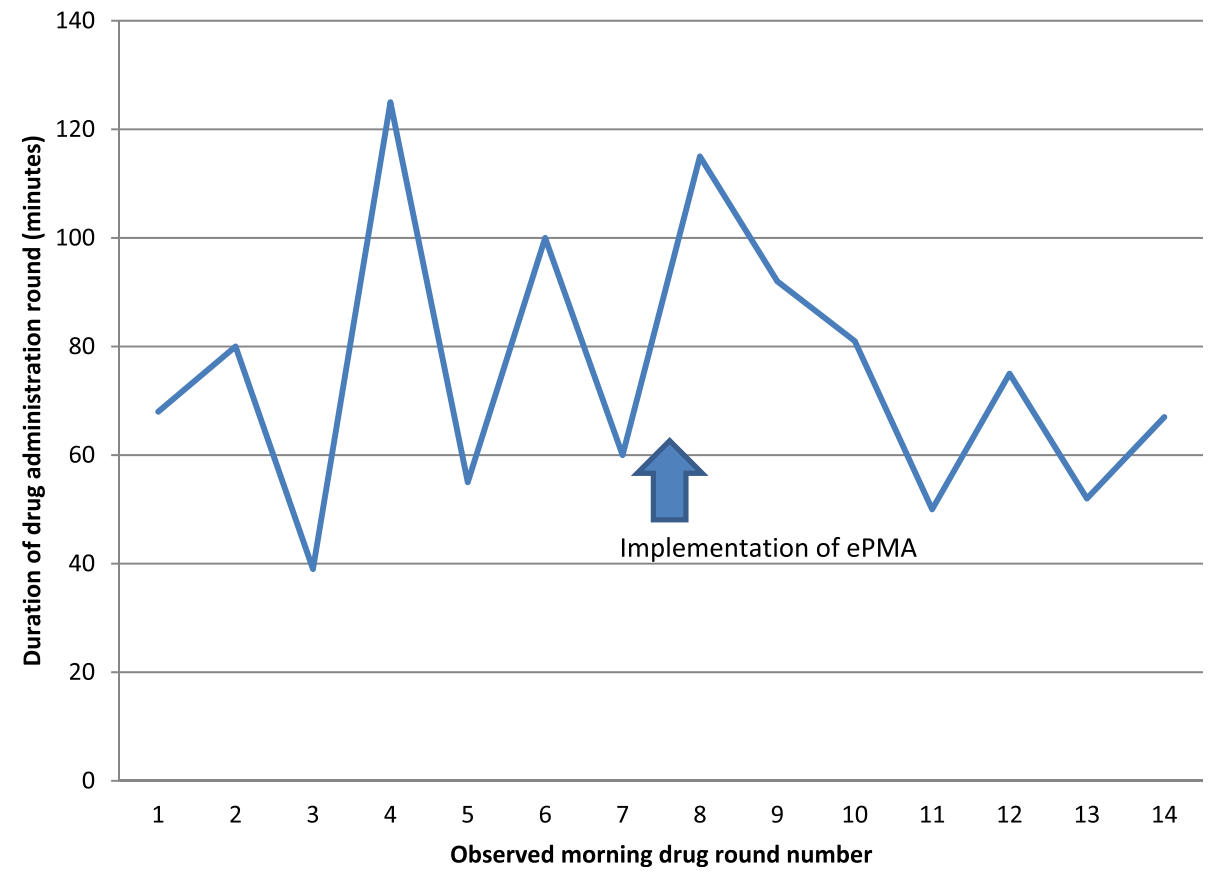

Fig. 1 Duration of morning drug rounds over time, pre- and post-ePMA. ePMA = Electronic Prescribing and Medication Administration

Post-ePMA, nurses in one of the ward bays no longer retrieved their medication from the treatment room, as this bay had a medication trolley with a computer incorporated. Post-ePMA, some drug rounds included both electronic and paper drug charts. To simplify the round, some nurses would give medication to patients with either electronic or paper charts first, retracing their steps for those patients who had the other type of chart.

\section{Interruptions during the drug round}

The observer observed 97 interruptions pre-ePMA, a mean of 4.4 (95\% CI 1.7 \%-7.1 \%) per hour. Post-ePMA there were 91 interruptions, with a mean of 4.7 (95\% CI 0.9 \%-8.5 \%) per hour. While there was no statistically significant difference in the overall interruption rate, there was a change in the sources of interruption (Fig. 6).

Both pre- and post-ePMA, the most common interruptions were 'healthcare related conversation' and 'nonhealthcare related conversation', with a change in the proportions of each. 'Healthcare related conversation' increased from $49.5 \%$ of all interruptions $(95 \%$ CI $39.5 \%-59.4 \%$ ) pre-ePMA, to $81.3 \%$ (95 \% CI $73.3 \%$ $89.3 \%)$ post-ePMA. 'Non-healthcare related conversation' reduced from $34.0 \%$ (95 \% CI $24.6 \%-43.5 \%$ ) preePMA to $14.3 \%$ (95 \% CI $7.1 \%-21.5 \%$ ) post-ePMA.

\section{Timeliness of medication administration}

We documented 198 medication administrations preePMA and 649 post-ePMA. Of these, 28 (14 \%) were not given to the patient pre-ePMA, and 79 (12\%) postePMA; these were generally due to the patient declining the medication or because it was not clinically appropriate.

There were 120 of 198 doses $(60.6 \%$; $95 \%$ CI $54.2 \%$ $67.8 \%)$ given within one hour of the scheduled time pre-ePMA and 481 of 649 (74.1\%; $95 \%$ CI $70.1 \%$ $77.9 \%)$ post-ePMA, suggesting that administration was significantly more timely post-ePMA. A small number of doses were administered more than two hours either side of the scheduled time both pre-ePMA (10 of 198; $5.0 \%$; $95 \%$ CI $2.0 \%-8.0 \%$ ) and post-ePMA (14 of 649; $2.2 \%$; 95 \% CI 0.9 \%-3.1 \%), with no statistically significant difference.

A specific issue identified related to the interval between paracetamol doses. Pre-ePMA the observer noted 18 occasions when oral paracetamol was administered with less than $3 \mathrm{~h}$ between successive doses; on two of these occasions the interval was little more than an hour. This was due to drug rounds starting late or early, and/or taking a long time. For example, on one occasion, the 6 pm evening drug round did not finish until $7.30 \mathrm{pm}$ when a dose of paracetamol was administered, and the night time drug round started at $8.40 \mathrm{pm}$ when a subsequent dose of paracetamol was given to the same patient. This phenomenon was not observed post-ePMA, possibly because the actual time a dose is given is recorded explicitly by the ePMA system. The default ePMA dosing schedule for paracetamol also meant that lunchtime doses of paracetamol were scheduled for $2 \mathrm{pm}$ rather than noon. 


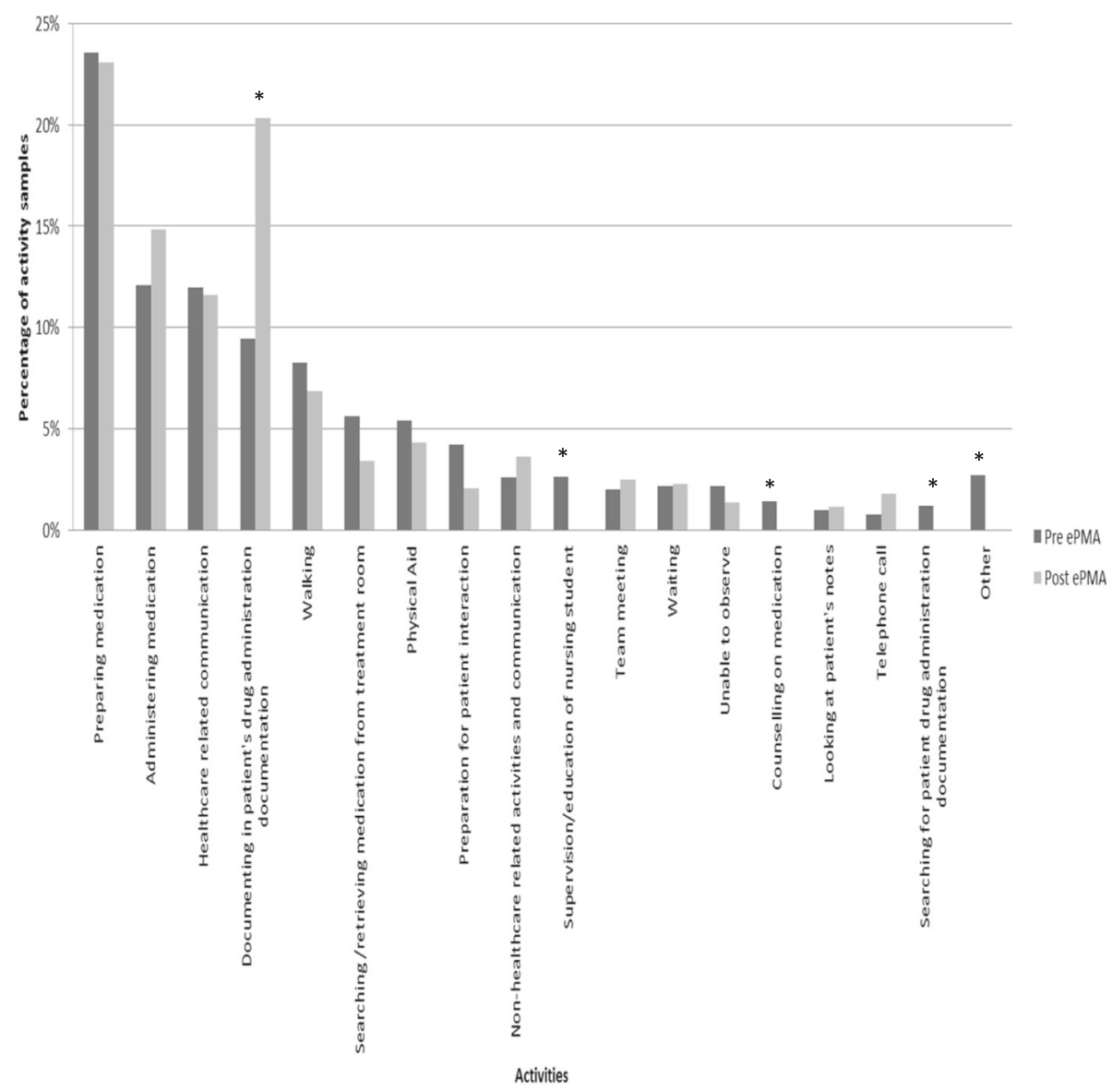

Fig. 2 Nurses activities during drug rounds. ePMA = Electronic Prescribing and Medication Administration. ${ }^{*}=$ Statistically significant based on calculated $95 \%$ confidence intervals

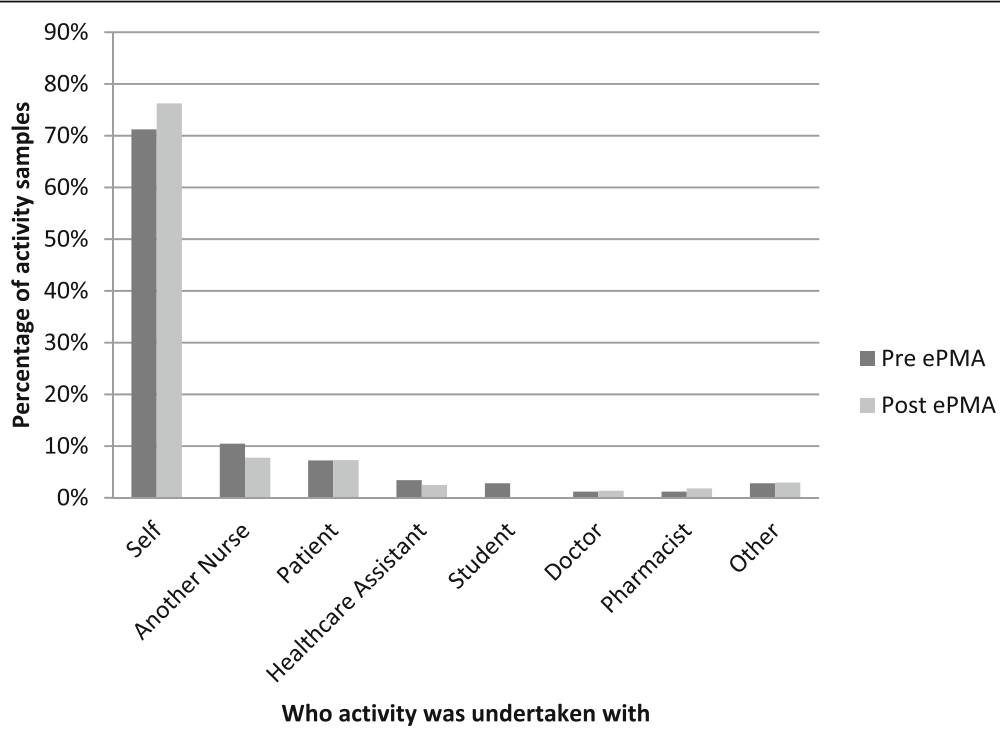

Fig. 3 Who the activities were undertaken with during drug rounds. ePMA = Electronic Prescribing and Medication Administration 


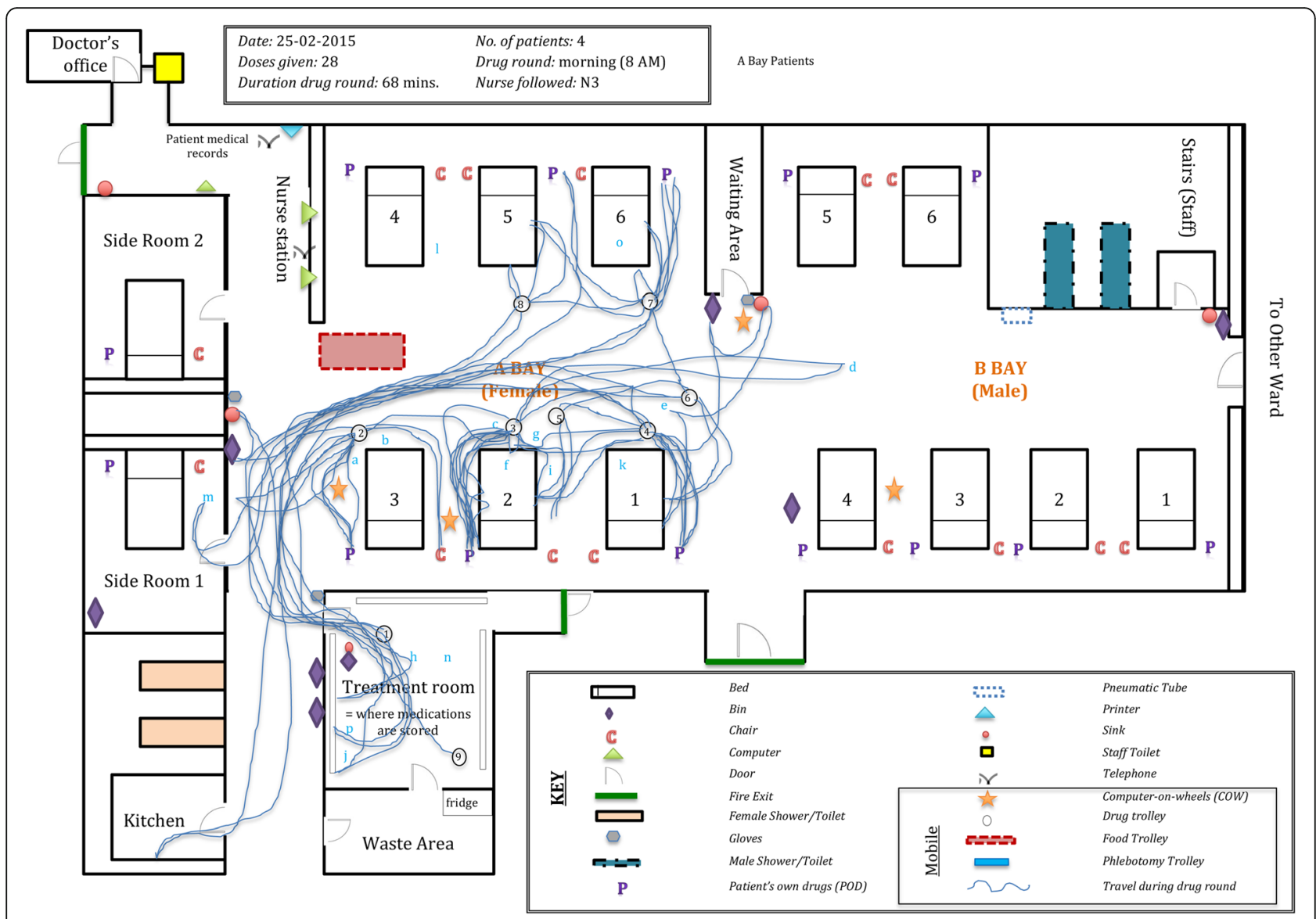

Fig. 4 Example of a spaghetti diagram pre-ePMA

\section{Discussion}

\section{Key findings}

Our findings suggest that while the introduction of ePMA does not significantly affect the length of time spent on drug administration rounds, it alters the distribution of tasks with a doubling of the time spent on documentation. As might be expected, it eliminates time spent searching for paper drug charts. Again, while there was no statistically significant change in interruption rate, the types of interruption changed with an increase in healthcare related interruptions and a decrease in non-healthcare related interruptions. The timeliness of medication administration improved, representing a potential improvement in relation to patient safety.

\section{Comparison with previous studies}

Our focus on scheduled drug rounds, rather than the entire working day, limits comparison with some previous studies [12]. Our findings also differ to a previous study that reported a reduction in drug administration round duration [3]. However, our observations continued throughout the immediate post-ePMA implementation period, and so may include an initial settling in period; in Fig. 1 the drug round duration appears to be decreasing over time post-ePMA, although data collection ceased one month after implementation so we cannot comment on any subsequent patterns.

\section{Interpretation and implications for practice}

There seems to be the potential for ePMA to improve the timeliness of medication administration, although this is likely to depend on how the system is used in practice. In the present study, this is possibly because the ePMA system prompts for a reason if a dose is administered more than an hour before or after its scheduled time, and if a dose is not given within two hours, the system generates an alert. The issue of paracetamol dosing intervals may need to be explored more widely in others areas where paper-based medication administration records are used, as the short dosing intervals observed represent a potential risk that has not been previously reported.

ePMA seems to reduce time spent on some activities, particularly those relating to searching for medication or drug charts, but there was an increase in interruptions 


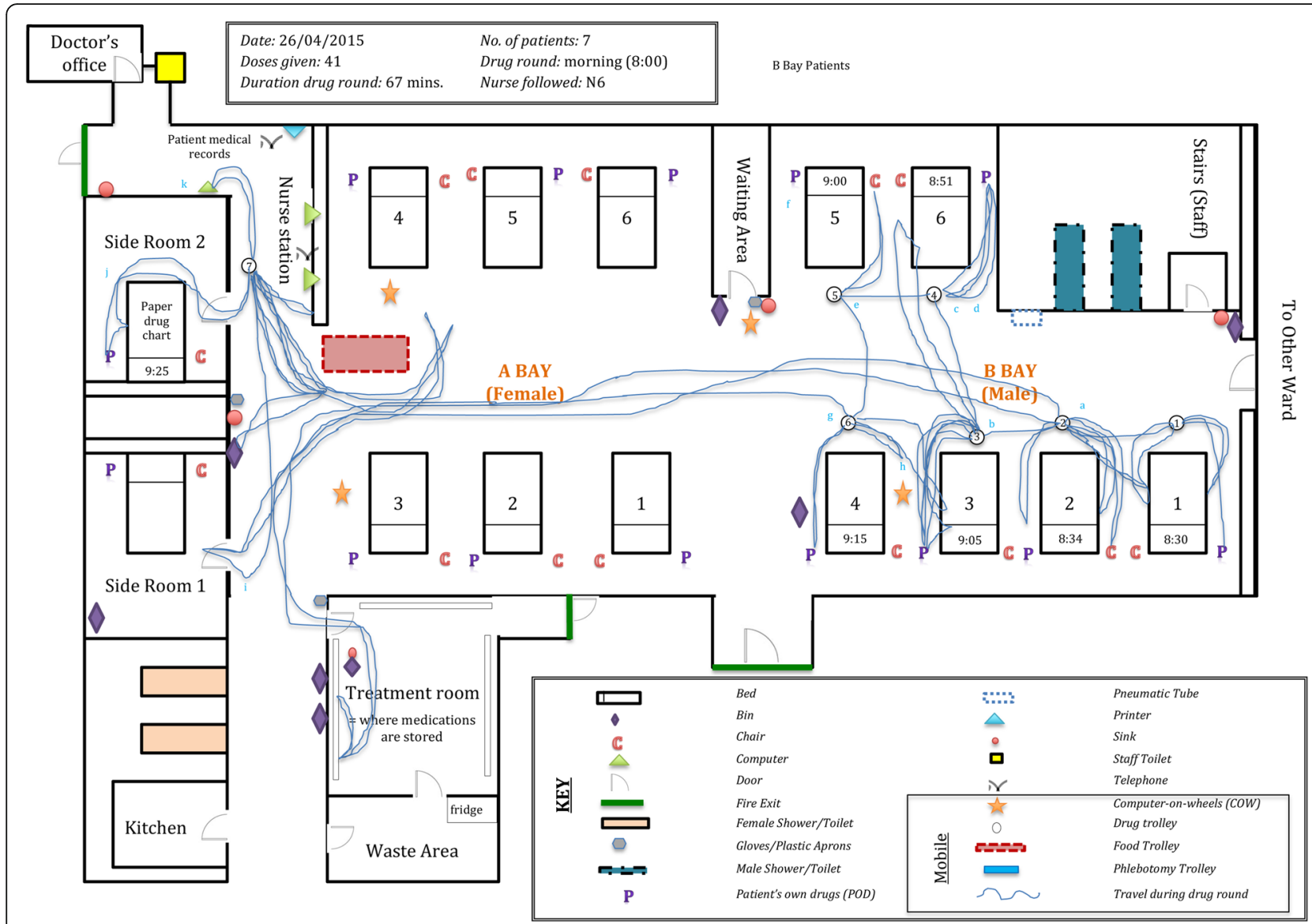

Fig. 5 Example of a spaghetti diagram post-ePMA

for healthcare related conversation, possibly representing questions about the ePMA system from other healthcare professionals. The doubling of documentation time was outweighed by a reduction in time spent on activities such as counselling on medication, supervision of nursing students and searching for documentation, meaning that the total drug administration round time remained similar. Some possible reasons for the increase in documentation time are the requirement to $\log$ into the ePMA system, the time taken to navigate to the appropriate screen and the need to sign each dose electronically.

The reduction in counselling on medication during the drug round post-ePMA, could suggest a negative consequence of ePMA. As we did not observe the nurses outside of drug rounds, we are unable to determine if counselling on medication occurred separately; this may be an important area for future research.

\section{Strengths and weaknesses}

This study is one of the first to look at the effects of ePMA on nurses' work. A strength was that one observer collected all data and so data collection and analysis were consistent. Limitations include a potential lack of generalisability as only one ward was studied, and a relatively small sample size. There was no control group and we therefore cannot rule out other concomitant influences on practice around the same time as ePMA implementation. There were differences in the number of rounds and doses observed pre- and post-ePMA, this is because it was easier post-ePMA to check the system to confirm the observed doses were actually given. We cannot rule out a Hawthorne effect due to the observer's presence [21]. We did not collect data on medication-related practices outside of scheduled drug rounds nor continue collecting data beyond the initial one month post-implementation period due to time constraints and limitations of available observer resource. We did not take into account multiple comparisons across the 18 activity categories in Fig. 2; calculation using the more stringent $99 \%$ CIs to take this into account suggests that the increase in documentation time, and the decrease in time spent on medication counselling and student supervision remain statistically significant. 


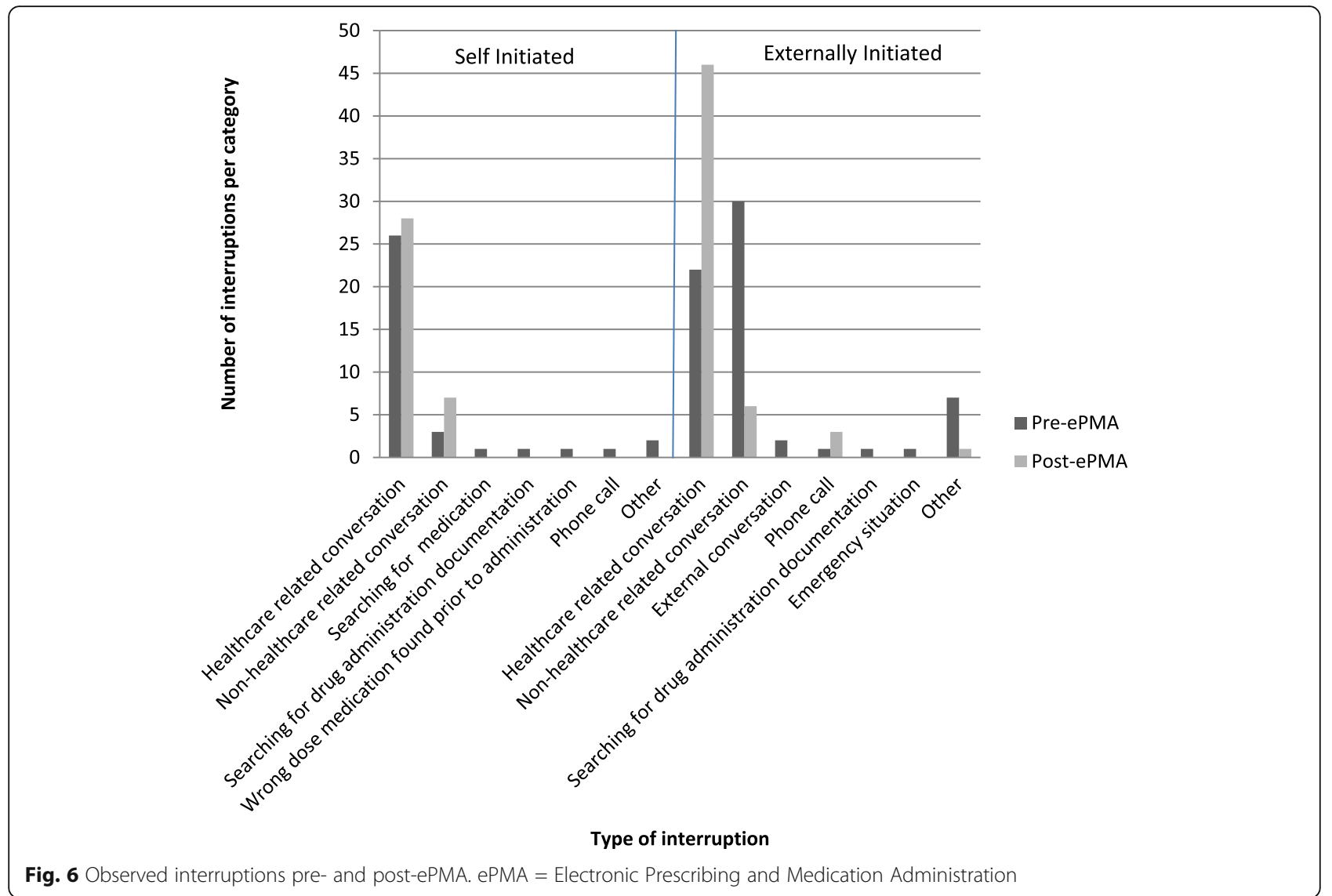

Fig. 6 Observed interruptions pre- and post-ePMA. ePMA = Electronic Prescribing and Medication Administration

\section{Implications for future research}

Future studies should consider additional use of a pedometer to collect quantitative data regarding distances walked, and explore the impact on work practices months or years after implementing ePMA. These studies should be on different wards and could also include observations on medication administration errors, and include intravenous drug administration, user acceptability and the perceived impact of ePMA. Larger studies would provide better power to detect differences in quantitative outcome measures, and should consider the effect of ePMA on medication-related work practices outside of scheduled drug rounds.

\section{Conclusion}

This exploratory study suggests that introduction of ePMA does not significantly affect the length of time spent on drug administration rounds, but alters the time spent on different tasks with a doubling of the time spent on documentation. No difference in interruption frequency was identified. The timeliness of medication administration improved, representing a potential patient safety benefit.

\section{Additional file}

Additional file 1: Nurses' activities data collection form - random interval work sampling. (DOC $2923 \mathrm{~kb}$ )

\section{Abbreviations}

ePMA: Electronic Prescribing and Medication Administration; USA: United States of America; UK: United Kingdom

\section{Acknowledgements}

The authors would like to thank both Seetal Jheeta and Monsey McLeod for their assistance.

\section{Funding}

This paper represents independent research supported by the National Institute for Health Research (NIHR) Imperial Patient Safety Translational Research Centre. The views expressed are those of the author(s) and not necessarily those of the NHS, the NIHR or the Department of Health.

\section{Availability of data and materials}

The datasets generated and/or analysed during the current study are available from the corresponding author on reasonable request.

\section{Authors' contributions}

AVW collected, analysed and interpreted the data. HB created the figures. HB and BDF were major contributors in writing the manuscript. All authors read and approved the final manuscript.

\section{Competing interests}

The authors declare that they have no competing interests. 


\section{Consent for publication}

Not applicable.

\section{Ethics approval and consent to participate}

Research ethics approval was not required as the project was approved locally as a service evaluation.

\section{Author details}

'Research Department of Practice and Policy, UCL School of Pharmacy, London, UK. ${ }^{2}$ Centre for Medication Safety and Service Quality, Imperial College Healthcare NHS Trust, London, UK.

Received: 1 July 2016 Accepted: 13 September 2016

Published online: 29 September 2016

\section{References}

1. Connecting for Health. Electronic Prescribing in Hospitals, Challenges and Lessons Learnt. http://webarchive.nationalarchives.gov.uk/20130502102046/ http://www.connectingforhealth.nhs.uk/systemsandservices/eprescribing/ challenges/Final_report.pdf Accessed 24 March 2016

2. Stephen Goundrey-Smith. Information Technology in Pharmacy: an Integrated Approach. London: Springer Science \& Business Media; 2012 http://www.springer.com/in/book/9781447127796 Accessed 24 March 2016

3. Franklin BD, O'Grady K, Donyai $\mathrm{P}$, Jacklin A, Barber $\mathrm{N}$. The impact of a closed-loop electronic prescribing and administration system on errors, administration errors and staff time: a before-and-after study. Qual Saf Health Care. 2007;16(4):279-84.

4. Franklin BD, Jacklin A, Barber N. The impact of an electronic prescribing and administration system on the safety and quality of medication administration. Int J Pharm Prac. 2008;16:1-5.

5. Ahmed Z, McLeod MC, Barber N, Jacklin A, Franklin BD. The use and functionality of electronic prescribing systems in English acute NHS trusts: a cross-sectional survey. PLoS One. 2013;8(11):e80378. doi:10.1371/journal. pone.0080378

6. Asaro P, Baxerman SB. Effects of computerized provider order entry and nursing documentation on workflow. Acad Emerg Med. 2008;15:908-15.

7. Yen K, Shane EL, Pawar SS, Schwendel ND, Zimmanck RJ, Gorelick MH. Time motion study in a pediatric emergency department before and after computer physician order entry. Anal Emerg Med. 2008;09:018.

8. Brock TP, Franklin BD. Differences in pharmacy terminology and practice between the United Kingdom and the United States. Am J Health Syst Pharm. 2007:64:1541-6.

9. Barber N, Cornford T, Klecun E. Qualitative evaluation of an electronic prescribing and administration system. Qual Saf Health Care. 2007:16:271-8.

10. Pirnejad H, Niazkhani Z, van der Sijs H, Berg M, Bal R. Impact of a computerized physician order entry system on nurse-physician collaboration in the medication process. Int J Med Inform. 2008;77:735-44.

11. Niazkhani Z, Pirnejad $H$, van der Sijs $H$, de Bont A, Aarts J. Computerized provider order entry system - does it support the inter-professional medication process? Lessons from a Dutch Academic Hospital. Method Inform Med. 2010;49:20-7.

12. Westbrook JL, Li L, Georgiou A, Paoloni R, Cullen J. Impact of an electronic medication management system on hospital doctors' and nurses' work: a controlled pre-post, time and motion study. J Am Med Inform Assn. 2013:20:1150-8.

13. Khajouei R, Wierenga PC, Hasman A, Jaspers MWM. Clinicians' satisfaction with CPOE ease of use and effect on clinicians' workflow, efficiency and medication safety. Int J Med Informs. 2011;80:297-309.

14. Niazkhani Z, Pirnejad H, Berg M, Aarts J. The impact of computerized provider order entry systems on inpatient clinical workflow: a literature Review. J Am Med Inform Assn. 2009:16(4):539-49.

15. $M^{C}$ Leod M, Barber N, Franklin BD. Facilitators and Barriers to Safe Medication Administration to Hospital inpatients: A Mixed Methods Study of Nurses Medication Administration Processes and Systems (the MAPS study). PLoS ONE, 2015; doi:10.1371/journal.pone.0128958

16. Beech $\mathrm{E}$, Barber $\mathrm{N}$. The development of a self-reporting multi-dimensional work sampling measure to study ward pharmacy services in the United Kingdom. J Soc Admin Pharm. 1993:10(4):157-62.

17. Franklin BD, O'Grady K, Donyai $P$, Jacklin A, Barber N. The impact of a closed loop electronic prescribing and automated dispensing system on the ward pharmacists time and activities. Int J Pharm Prac. 2007;15:133-9.
18. Brixey JJ, Robinson DJ, Johnson CW, Johnson TR, Turley JP, Zang J. A concept analysis of the phenomenon interruption. Adv Nurs Sci. 2007:30:E26-42.

19. $M^{c}$ CallumLayton. Confidence interval calculator. https://www.mccallumlayton.co.uk/tools/. Accessed 20 May 2015

20. Gardner M, Altman D. Statistics with Confidence - Confidence intervals and statistical guidelines. London: British Medical Journal; 1995.

21. Schnelle J, Ouslander J, Simmons S. Direct observations of nursing home care quality: does care change when observed? J Am Med Dir Assoc. 2006:7:541-4

\section{Submit your next manuscript to BioMed Central and we will help you at every step:}

- We accept pre-submission inquiries

- Our selector tool helps you to find the most relevant journal

- We provide round the clock customer support

- Convenient online submission

- Thorough peer review

- Inclusion in PubMed and all major indexing services

- Maximum visibility for your research

Submit your manuscript at www.biomedcentral.com/submit
Biomed Central 